Proceedings

\title{
Atrium Impact on a School-Building: Thermal Performance in a Hot Climate ${ }^{+}$
}

\author{
José Antonio Romero-Odero, Carmen Galán-Marín * and Carlos Rivera-Gómez \\ Departamento de Construcciones Arquitectónicas 1, Escuela Técnica Superior de Arquitectura, \\ Universidad de Sevilla, Avfa. Reina Mercedes, 2, 41012 Seville, Spain; jrodero@us.es (J.A.R.-O.); \\ crivera@us.es (C.R.-G.) \\ * Correspondence: cgalan@us.es; Tel.: +34-954-556-591 \\ + Presented at the 5th Ibero-American Congress on Entrepreneurship, Energy, \\ Environment and Technology-CIEEMAT, Portalegre, Portugal, 11-13 September 2019.
}

Published: 17 January 2020

\begin{abstract}
The process of climate change has increased the planet's mean temperature. An example of this are the $44.3^{\circ} \mathrm{C}$ registered in July in the cities of Córdoba and Seville (Spain). In this scenario, the educational centers in Andalusia, mostly built during the 20th century, are unable to reach the thermal comfort inside the classrooms throughout the year, without resorting to mechanical air conditioning procedures. This study simultaneously monitors indoors, outdoors and transitional spaces of a case study to verify the effectiveness of the passive cooling systems and the Atrium thermal effect of the building. Our results demonstrate that temperatures inside classrooms are influenced by the orientation and their air circulation (atrium or outdoor) and as expected, the higher temperature in the building are registered in the classrooms in the last floor.
\end{abstract}

Keywords: outdoor and indoor air temperature; atrium monitoring; adaptive thermal comfort; building energy savings; free running buildings

\section{Introduction}

At present we have a large number of buildings inherited from the cities transformation process which, due to their constructive characteristics, are far from satisfying today's needs by contemporary society. In the case of Spain, these buildings have been built mostly prior to the release of the Technical Building Code (CTE), the Spanish regulation establishing the basic requirements to be applied to new buildings. Moreover, not only the comfort demands in buildings have increased, but the planet temperature has raised because of global warming. In areas of warm climates, the temperatures are more extreme, reaching records of around $45^{\circ} \mathrm{C}$ during the summer months of July and August. Consequently, many complaints from the educational community have recently jumped for being affected by the temperature increase inside the classroom. Strikes and demonstrations have been frequent during the last months of the academic year (May and June), even reaching the suspension of the teaching. As a consequence, a new social movement called "Schools of Heat" has necessarily arisen in several Andalusian cities, through which centers, represented by the associations of mothers and fathers of the pupils (AMPA), are mobilized seeking to improve the air conditioning of the public centers.

In view of this new situation, it is clear the social urgency of facing the problems detected in schools, which due to their construction dates, seem to have become obsolete. To this purpose, it necessary (i) to enhance the value and recognition of these constructions by making the population and the scientific community aware of the current state in which they are, and (ii) to respond to the problem from the context of adaptation to climate change in which today we find ourselves [1]. 
There are numerous studies that support the use of thermodynamics of transition spaces as a passive bioclimatic strategy [2-4]. These can be applied from a study focused on intervention in existing buildings in the school environment, in order to help reduce the high temperatures detected in the classroom. In educational buildings, transition spaces are of particular importance. Depending on the educational level taught in the center, the space of the patio is employed with more or less intensity by the students. But in any case, it is a space where horizontal relationships are established with each other, which, in one way or another, collaborate and adding value to the learning process [5].

Therefore, the aim is to focus the results of the study of the thermodynamic behaviour of the transition spaces in the teaching buildings to adapt them to the requirements of habitability, energy and sustainable that are demanded today [6].

\section{Materials and Methods}

In order to carry out the experimental study of the thermodynamic functioning of the transition spaces, it is essential to know constructively and functionally the building. In such a way, we can establish the monitoring and data-taking campaigns in a suitable way by means of the:

- Presentation and definition of the case study. This section establishes the analysis of the current state of the building. This includes general data, planimetry, catalog of photographs.

- Design of the monitoring campaign. The necessary instrumentation will be established to monitor the case-study (Figure 1), its location in the building and the space of time it shall cover.

- Development of the monitoring campaign. You will have to prepare the material is prepared and assembled following the designed campaign previously established.

- Extraction and preparation of data obtained. Once the measurement campaign is completed, the information collected by the material is extracted.

- Analysis and conclusions. As a final section, the conclusions established by the results obtained throughout the course will be reflected in it.

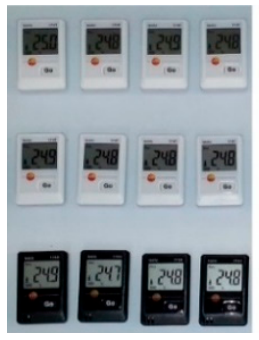

(a)

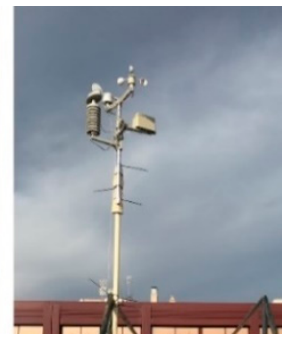

(b)

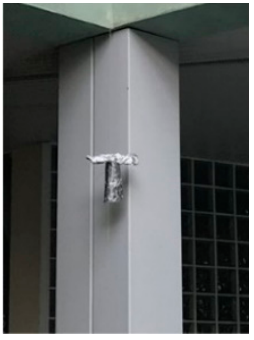

(c)

Figure 1. Instruments are measuring devices used for tests. (a) sensors of measurement (temperature and humidity); (b) meteorological station, to be placed in the building cover; (c) protective caps to prevent overheating of the sensor by direct radiation.

\section{Presentation Case-Study}

The building selected as an experimental case study is the Public high school "IES Murillo", located in the center of the City of Seville. It was built in 1991, under the supervision of a different regulation to the existing one. Therefore, different requirements were demanded in terms of user comfort and energy-saving requirements.

In essence, this is a $70 \mathrm{~m} \times 50 \mathrm{~m}$ rectangular floor building, with two inner atriums enclosed by a polycarbonate cover of a cell $(1 \mathrm{~cm})$. On the ground floor, the building is organized in two longitudinal bands, hosting the most public use program (Library, auditorium, gymnasium). In the upper floors the classrooms and departments are located distributed around the atriums, which in numerous cases act as the space of ventilation and entrance of natural light (Figure 2). 


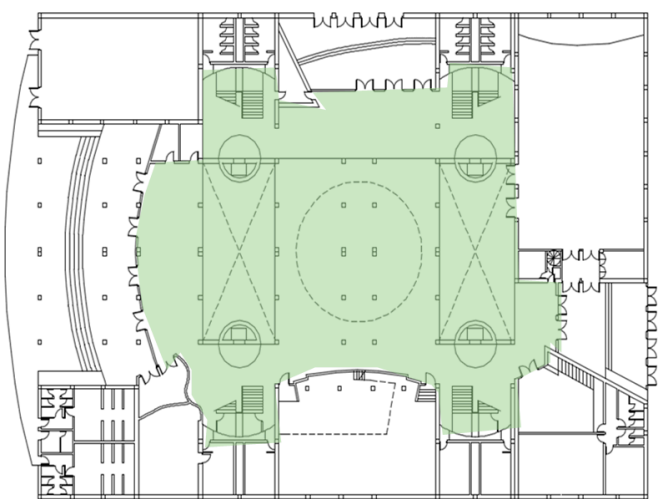

(a)

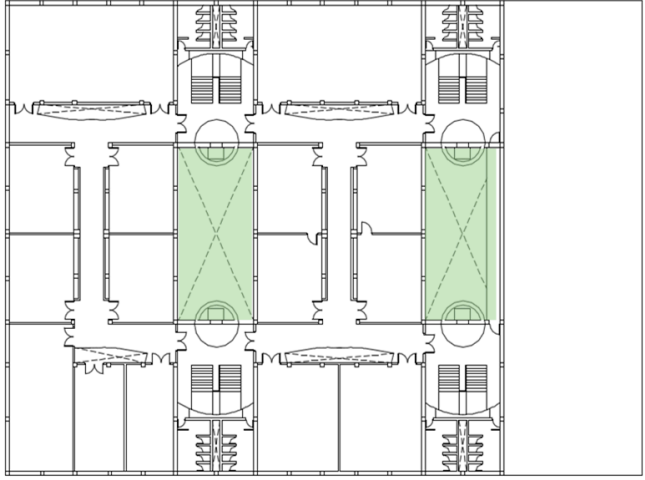

(b)

Figure 2. Set of drawings: (a) Ground floor $+0.00 \mathrm{~m}$; (b) Second floor $+8.30 \mathrm{~m}$.

Both transitional spaces will be called from now on the "Northern Atrium" and the "Southern Atrium". Due to their locations in the building, they will be the protagonists of the thermodynamic study to be performed. Despite having openings to ventilate on the roof, these spaces were conceived as interior spaces on the original project. This is why their facades have a composition of gypsum boards and air chambers, without thermal insulation. Besides, as a singularity, the northern Atrium has a large glazed surface $(18.2 \times 9 \mathrm{~m})$ facing the north, and the southern atrium has a palm tree inside.

\section{Results}

In the first place, general graphs of the whole period in which all the data collected by the sensors in parallel with the data obtained by the meteorological station are represented. So far, the winter campaign is the only one that has been carried out. It took place during the winter holidays, so the occupation of the building turns out to be null. This way, it is possible to analyze the thermodynamic operation without additional loads. With these graphical resources, we demonstrated the tempering function of the transition space, and measured the maximum and minimum temperatures, the days with a greater gap between outdoor and atrium temperatures.

A specific day was selected in order to deepen in the temperature analyses. In this case, the day with the greatest thermal amplitude (in other words, the day with the highest difference between the maximum indoor temperature and the minimum outdoor one), and the behavior of the north and south Atriums were compared (Figures 3 and 4).

Figure 3 shows that the thermal behavior of the transition space (i.e., atrium) evolves according to the variation of the outdoor temperature. This allows analyzing the need or not of air conditioning at any time. 

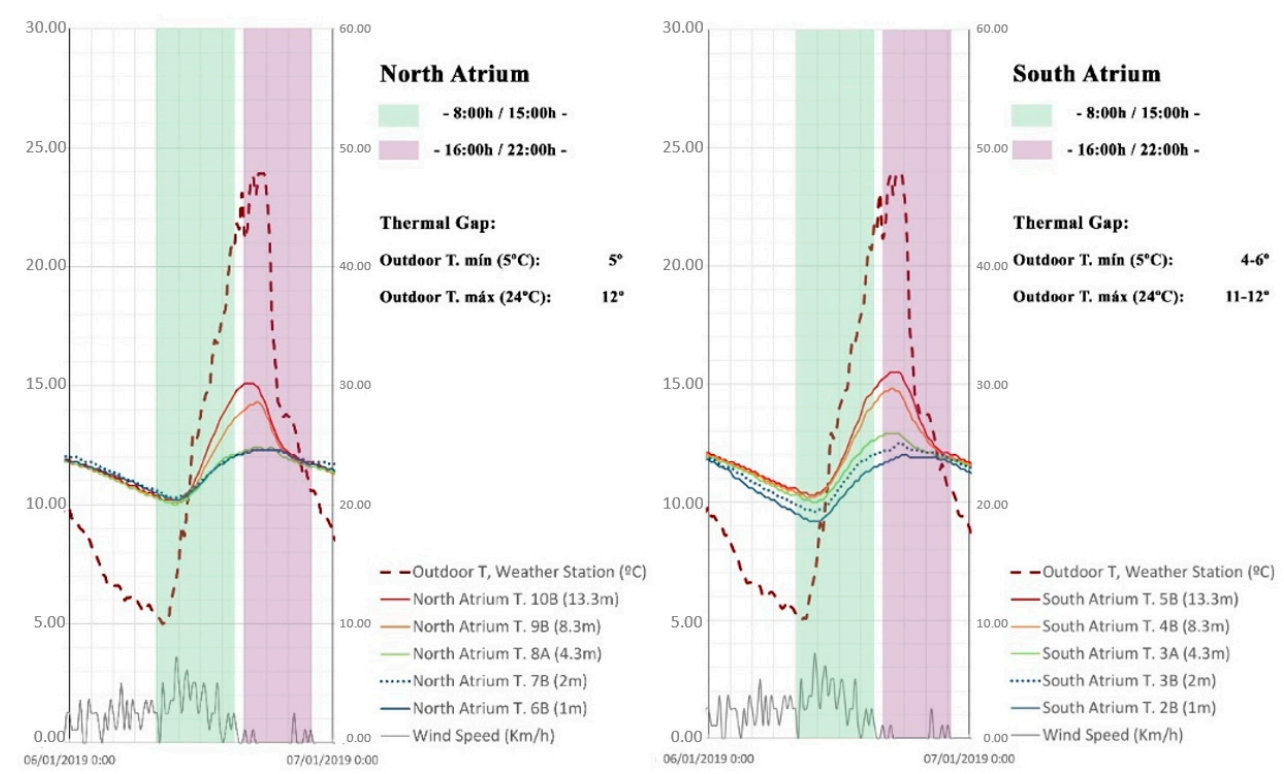

Figure 3. Comparative behavioral thermodynamic between the atriums. Note that the timetable of the morning and evening occupations of the building is indicated in green and purple respectively.

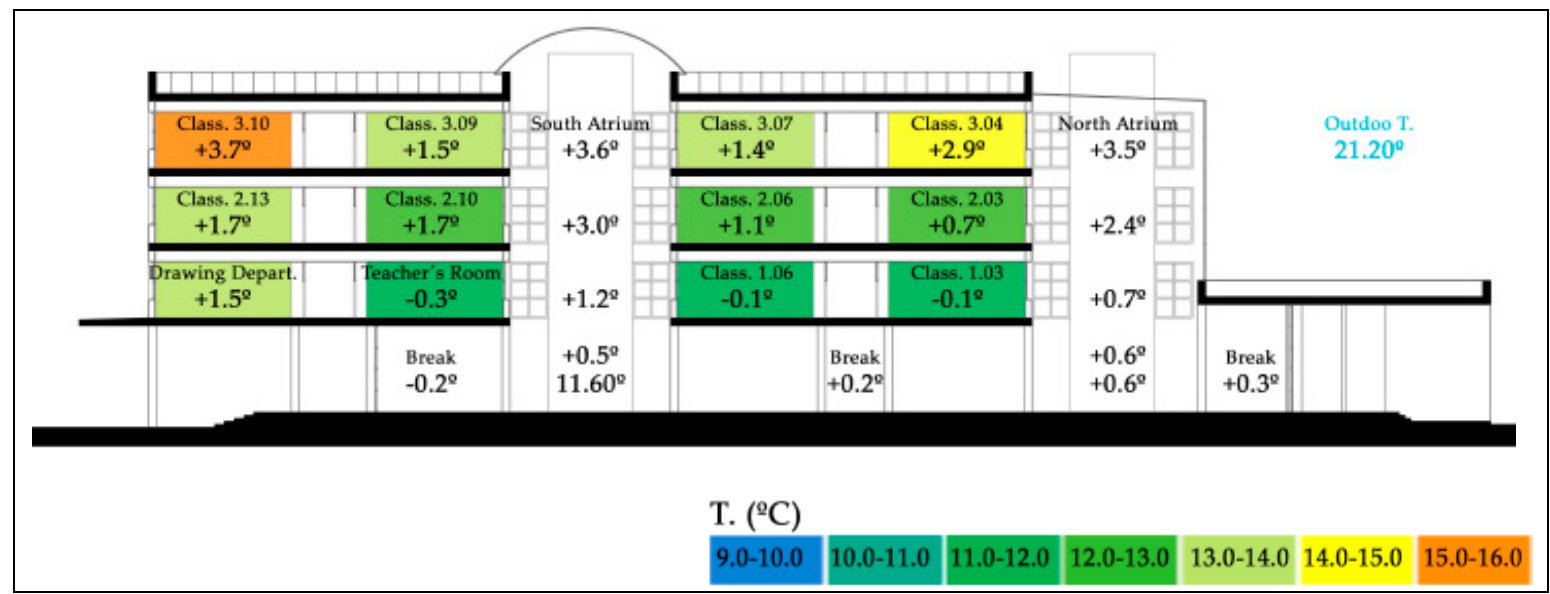

Figure 4. Thermal gaps correlation between classrooms and transitional spaces at 16:00 h (6 January 2019).

Figure 4 shows that the temperature inside both of atriums remains constant over time relative to the changes in the classroom temperatures. The atriums never get as much as warm or cool as the outdoor, therefore acting as tempering element with both cold and warm temperatures. The existence of the polycarbonate cover along with the low ventilation and renovation of air in the atriums causes the heat to accumulate at the top of these spaces, leading to higher temperatures in them relative to lower levels. No stratification is detected in the sensors located at the bottom of the Northern atrium, contrarily to what happens in the southern atrium.

\section{Conclusions}

Our study reinforces the hypothesis of the tempering functioning of the transition spaces, being used as passive energy-saving tools. The existence of a translucent cover on the transition spaces affects positively during the winter campaign because it stores heat during the day with the solar incidence, performing the function of energy accumulator. In the next step of our study the operation of this same spaces during the summer months will be monitored. 
Author Contributions: J.A.R.-O. designed and performed the experiments; C.G.-M. and C.R.-G. supervised the process; J.A.R.-O., C.G.-M. and C.R.-G. analyzed the data and wrote the paper.

Acknowledgments: This work has been supported by the National Government of Spain Research Projects MTM2015-64577-C2-2-R and RTI2018-093521-B-C33. The authors thank AEMET (State Meteorological Agency) for the data supplied.

Conflicts of Interest: The authors declare no conflict of interest. The funders had no role in the design of the study; in the collection, analyses, or interpretation of data; in the writing of the manuscript, or in the decision to publish the results.

\section{References}

1. EU Climate Action. Available online: https://ec.europa.eu/clima/citizens/eu_es (accessed on 6 January 2019).

2. Taleghani, M.; Tenpierik, M.; van den Dobbelsteen, A. Environmental impact of courtyards-A review and comparison of residential courtyard buildings design in different climates. J. Green Build. 2012, 7, 113-136.

3. Rojas, J.M.; Galán-Marín, C.; Fernández-Nieto, E.D. Parametric study of thermodynamics in the Mediterranean courtyard as a tool for the design of eco-efficient buildings. Energies 2012, 5, 2381-2403.

4. Jara, E.Á.R.; de la Flor, F.J.S.; Domínguez, S.Á.; Lissén, J.M.S.; Rincón Casado, A. Characterizing the air temperature drop in Mediterranean courtyards from monitoring campaigns. Sustainability 2017, 9, 1401.

5. Burman, E.; Kimpian, J.; Mumovic, D. Building Schools for the Future: Lessons Learned from Performance Evaluations of Five Secondary Schools and Academies in England. Front. Built Environ. 2018, 4, article 22.

6. Añón-Abajas, R.M.; Châtelet, A.M.; López-Santana, P.; Larripa Artieda, V.; Loren-Méndez, M.; PizónAyala, D.; Quesada-Arce, A.B.; Sentieri Omarrementería, C.; Verdejo Álvarez, E.; de Diego Ruiz, P.; et al. Arquitectura Escolar y Educación; Proyecto, Progreso, Arquitectura. N17; Universidad de Sevilla: Sevilla, Spain, 2017; ISSN 2171-6897 and 2173-1616.

(C) 2019 by the authors. Licensee MDPI, Basel, Switzerland. This article is an open access article distributed under the terms and conditions of the Creative Commons Attribution (CC BY) license (http://creativecommons.org/licenses/by/4.0/). 